\title{
Research on Non-point Source Pollution Based on Spatial Information Technology: A Case Study in Qingdao
}

\author{
Tao Shen ${ }^{1}$, Jinheng Zhang ${ }^{2, *}$, and Junqiang Wang ${ }^{3}$ \\ ${ }^{1}$ College of Surveying and Mapping \& Urban Spatial Information, \\ Beijing University of Civil Engineering and Architecture Beijing, China, 100044 \\ ${ }^{2}$ Institute of Eco-environment \& Agriculture Information, \\ Qingdao University of Science and Technology, \\ Qingdao, Shandong 266042, China \\ zjh-nhle163.com \\ ${ }^{3}$ Qingdao Station for Popularizing Agricultural Techniques, Qingdao, Shandong 266000, China
}

\begin{abstract}
The paper discussed the research course of the non-point source pollution and the application of spatial information technology to the non-point source pollution. Then we collected some spatial information data such as terrain, soil, water system, land use and so on, used MUSLE equation supported by geographic information system to get the risk distributing map of the non-point source pollution in Qingdao. The study met with good results. The result showed that the spatial information technology is a powerful tool to research the non-point source pollution and it can powerfully provide the decision support for management and control of the non-point source pollution.
\end{abstract}

Keywords: non-point source pollution, modified universal soil loss equation, spatial information technology.

\section{Introduction}

Non-point source pollution refers to the atmosphere, surface and soil pollutants (municipal solid waste, rural livestock manure, chemical fertilizers in farmland, pesticides, heavy metals and other toxic substances or organic compounds) take the rain as the carrier and migrate to the surface runoff in the process of runoff generation and conflux under the action of eluviation and erosion of the rainfall runoff, thereby coming into receiving waters such as rivers, lakes, reservoirs, ocean waters and so on and causing pollution[1]. At present, the control and management of the point source pollution such as industrial and living pollution has gradually strengthened and achieved remarkable results as people deepened understanding of the importance of their hazards, and non-point source pollution impacting on the environment have become increasingly prominent[2]. Currently, many studies have confirmed that non-point source pollution

\footnotetext{
* Corresponding author.
} 
has become the major sources for the world-wide surface water and groundwater pollution, such as in the United States, there are approximately $60 \%$ pollution of the rivers and $50 \%$ pollution of the lakes related to the non-point source pollution[3]. In China, non-point source pollution is increasingly serious, the non-point source pollution in Taihu Lake and Dianchi Lake has become one of the important causation of the main lake water quality deterioration[4].

The study of the non-point source pollution in foreign started in the 50 to 60 years of the 20th century and the United States, Britain, Japan and other developed countries take the lead in this study. Particularly in the United States, there is a long research history, the United States is on of the few countries in the world carrying out the national system control study of the non-point source pollution[5]. The U.S. Department of Agriculture and other research institutions have developed a series of experience statistical model foe agricultural non-point source pollution, including SCS curve code and universal soil loss equation (USLE)[6]. In the late 90s of the 20th century, a number of very large and powerful watershed model has been developed. These models are all large professional software integrated spatial information processing, database technology, mathematical calculation and visualization. In these models, more well-known are the BASINS developed by the United States Environmental Protection Agency, the SWAT[7] developed by Arnold and the AnnAGNPS jointly developed by the U.S. Natural Resources Conservation Service and Agricultural Research Service. These models are widely used in the study of the continuous simulation to the regional rainfall - runoff, soil erosion and solute transport. They can be used to estimate the pollution load in order to identify the main pollution factors and critical source areas, and combined with the control and management measures.

The study of the non-point source pollution in China began in the late 80s of the 20th century. In this period, the study mainly focus on the study in the macroscopic characteristics, the pilot study in quantitative model of the agricultural non-point source pollution load[8] and the investigation of the lake eutrophication. As our country is not enough aware of the harm of the non-point source pollution, moreover the study of the non-point source pollution disjoints with the total amount control programs of the pollutants from the non-point source pollution, research means of our country isolated, scattered and mainly in the field of artificial simulation study and experiment on spot[9], and the non-point source pollution control measures are very weak. Although some studies have dealt the content of non-point source pollution load assessment, modeling and GIS integration technology [10], there are very few participants, lack systematic research and do not extend deep into the management and policy research. In recent years, with the understanding of non-point source pollution, the level of our study is also rising. The research on urban runoff pollution in Beijing [11] and the following study in the Yuqiao reservoir, Dianchi Lake, Taihu Lake, Chaohu Lake, Jinjiang River, Suzhou River, the Miyun Reservoir achieved fruitful results and accumulated useful experience [12-16].

Spatial information technology is a new technology rising in the 60 years of this century and developed rapidly in China after mid-70s, which mainly includes the theories and technologies of the remote sensing (RS), geographic information systems (GIS), Global Positioning System (GPS), and combined with computer technology and 
communication technology. This technology puts up spatial data collection, measurement, analysis, storage, management, display, dissemination and application.

With the development and wide application of spatial information technology, remote sensing and geographic information systems has become an important research technology of non-point source pollution. Remote sensing and geographic information systems can provide the accurate spatial information to monitor non-point source pollution and provide the surface characteristics of the the location of pollution. Remote sensing can also provides land use, vegetation cover DEM and other basic data to various non-point source pollution model, geographic information systems has strong spatial and temporal advantage in managing and analyzing geographic data, GPS data, soil data, weather data, environmental data, remote sensing data and agricultural management data. The study of non-point source pollution often requires large quantities of measured data, but nowadays the information available to both quantity and quality are still not satisfied, a lot of information to rely on field measurements is very difficult to study[17]. The emergence of remote sensing technology provides an effective means to solve these problems and creates favorable conditions for the development of these models because remote sensing is macroscopic, short-periodic and human, material, financial, and time savings. Geographic information system has powerful data processing capabilities, enabling people to analyze and process the geo-spatial data collected by the RS technology, and promote the development of the model. Non-point source pollution combined with RS and GIS technology has become a current focus of international research.

\section{The Research Process}

It is an effective technique to use the spatial information model to analyze the spatial and temporal distribution of non-point source pollution. USLE, the widely applied empirical model since the 60 years of the 20th century, only requires a few parameters to effectively describe and evaluate the non-point source pollution distribution after integrated with GIS. Sivertun[18] developed a modified USLE model(MUSLE) to achieve the rapid identification of risk areas of the non-point source pollution on the GIS platform, and so extended the USLE applications. In this paper, we make Qingdao as the research object and use MUSLE model to study the non-point source pollution in this region.

\subsection{Overview of the Study Area}

The study area, Qingdao is situated between $119^{\circ} 30^{\prime} \sim 121^{\circ} 00^{\prime} \mathrm{E}$ longitude and $35^{\circ} 35^{\prime} \sim 37^{\circ} 09^{\prime} \mathrm{N}$ latitude. Qingdao extends over a total area of $10654 \mathrm{~km} 2$. Qingdao receives an average annual rainfall of $775.6 \mathrm{~mm}$. Mountainous, plain regions, hilly region and lowland occupy the watershed the $15.5 \%, 37.7 \%, 25.1 \%$ and $21.7 \%$ of land area receptivity. 


\subsection{Research Methods}

This research uses MUSLE equation, which improved on the basis of USLE (Universal Soil Loss Equation) developed by the United States Department of Agriculture (USDA)[18]. It will help to apply GIS to evaluate the non-point source pollution risk area. The expression is as follows:

$$
P=K \bullet S \bullet W \bullet U
$$

In the formula (1): $\mathrm{P}$ is non-point source pollution risk, which expresses the risk of soil erosion and contaminants eluviations; $\mathrm{K}$ is the soil factor; $\mathrm{S}$ is the slope factor; $\mathrm{W}$ is the channel factor; $\mathrm{U}$ is the land-use factor.

Compared to the original USLE and other non-point source pollution model, the risk map generated by MUSLE equation does not give the actual pollution load information, but it can be used to identify the high erosion risk or impact area to the surface water quality in the study area. MUSLE model can be based on normal commercial GIS platforms (such as ArcView and ArcGIS) to apply and analyze. It usually uses the grid data to compute and the model requires spatial data as input parameter, including DEM, land use maps, soil maps and water maps. The process is shown in Figure 1.

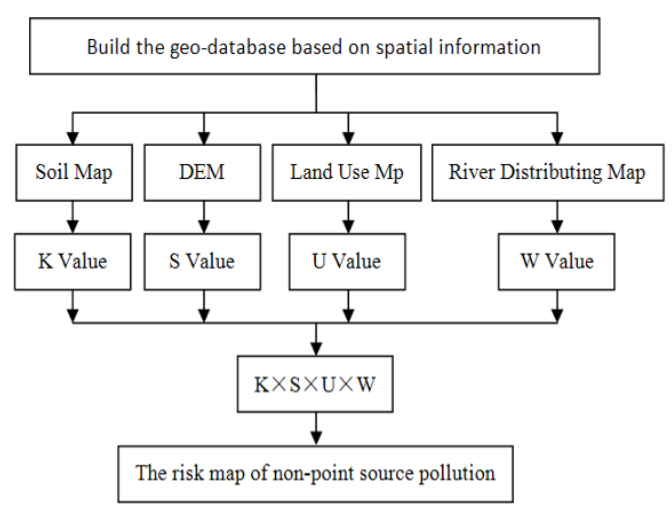

Fig. 1. The processing map of the non-point source pollution risk based on spatial information technology

\subsection{Compute Using Model}

\subsubsection{Data Preparation}

This research requires some spatial data including DEM, land use map, soil map and river map. All input data are used Albers Equal-Area Conic projection. Due to land-use data is interpreted from the TM remote sensing image, which grid size is $30 \mathrm{~m} \times 30 \mathrm{~m}$, so other spatial data are all turned to the same size. USLE equation is recommended for small area and the grid size used in this study basically meets the need.

(1) Soil map: the main soil classes in the study area are decided by the classification value given by McElroy et al [19], as shown in Table 1 . 
Table 1. Soil class in the study area

\begin{tabular}{cc}
\hline Class & Grid value \\
\hline Till & 0.380 \\
Water & 1.000 \\
Gravel & 0.200 \\
Clay & 0.450 \\
\hline
\end{tabular}

(2) Slope length map: in the ArcGIS 9.2, we load the Spatial Analyst module. The slope map is generated after filling depression for DEM and named slope, then we generate flow accumulation map in the Hydrology module. Before get slope length map, we must set the grid value of the rivers, lakes and other water bodies as 0 in order to avoid producing high values which do not meet the fact. The treated accumulation map is named Accumulation. Finally, run the following expression and get slope length map.

$\operatorname{Pow}([$ Accumulation $] * 86.1794 / 22.1,0.6) * \operatorname{Pow}(\operatorname{Sin}([$ slope $] * 0.01745) / 0.09,1.3) * 1.6$

(3) Land use maps: the main land use classes in the study area are decided by the classification value given by McElroy et al [19], as shown in Table 2.

Table 2. Land use class in the study area

\begin{tabular}{cc}
\hline Class & Grid value \\
\hline Water & 0.000 \\
Forest & 0.005 \\
Pasture & 0.010 \\
Urban & 0.030 \\
Other open & 0.100 \\
land & 0.100 \\
Agriculture & \\
\hline
\end{tabular}

(4) River map: we apply the distance tool to calculate each grid distance from the nearest water bodies and then calculation on the resulting grid maps (named distance), the expression is:

$$
0.6 /(\operatorname{Exp}(0.002 *[\text { distance }])-0.4)
$$

\subsubsection{The Results}

In this study, the model calculation is based on ArcGIS 9.2 platform, the main application of the GIS includes conversion function between vector data and raster data, re-classification function, search distance function and grid data computing function. First of all, we convert all layers to $30 \mathrm{~m} \times 30 \mathrm{~m}$ ESRI Grid format, then calculate in turn the slope length factor-S value (Figure 2), soil factor-K value (Figure 3), land-use factor-U value (Figure 4) and river factor-W value( Figure 5), which are the input parameters of the MUSLE model. 


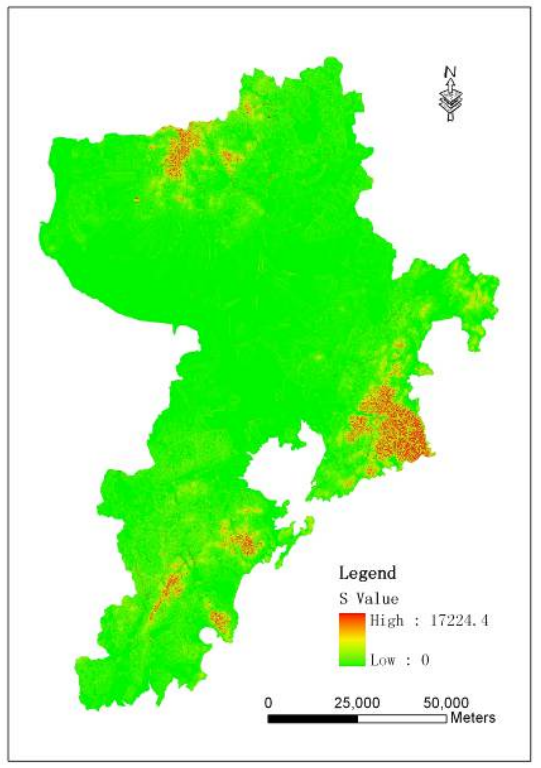

Fig. 2. The map of slope length factor

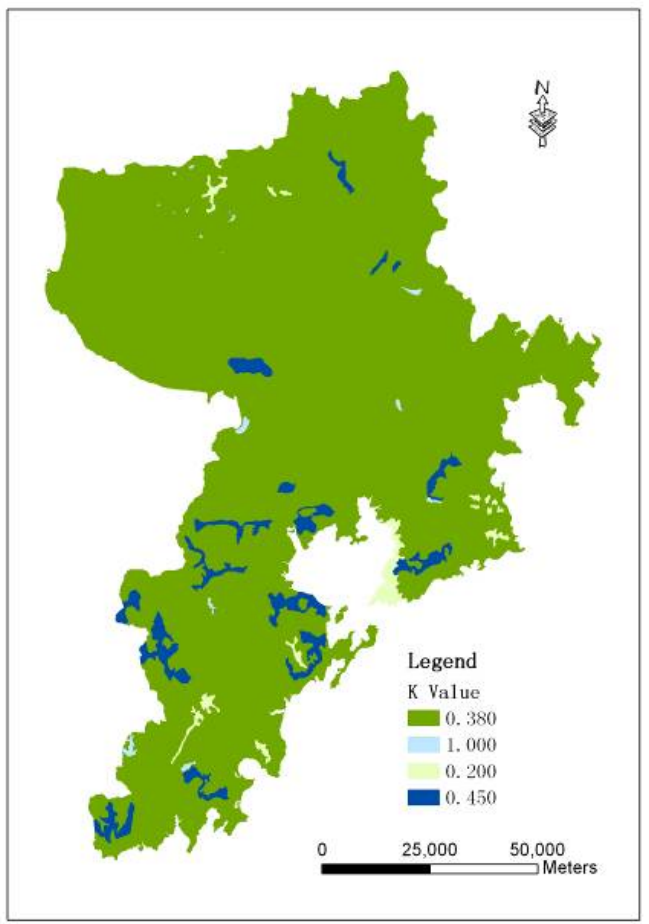

Fig. 3. The map of soil factor 


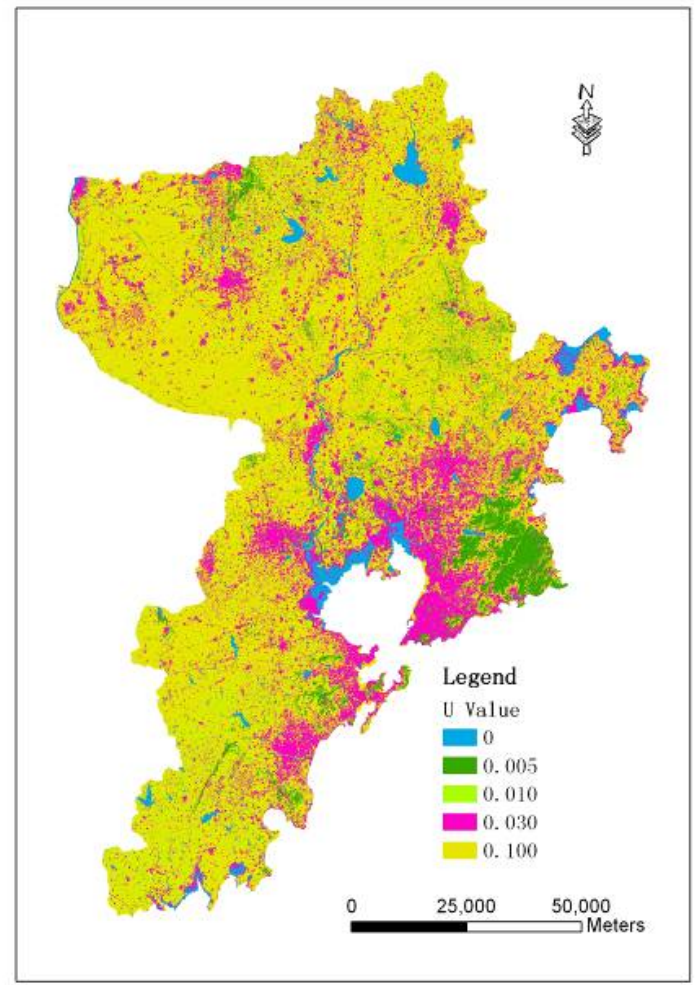

Fig. 4. The map of land-use factor 


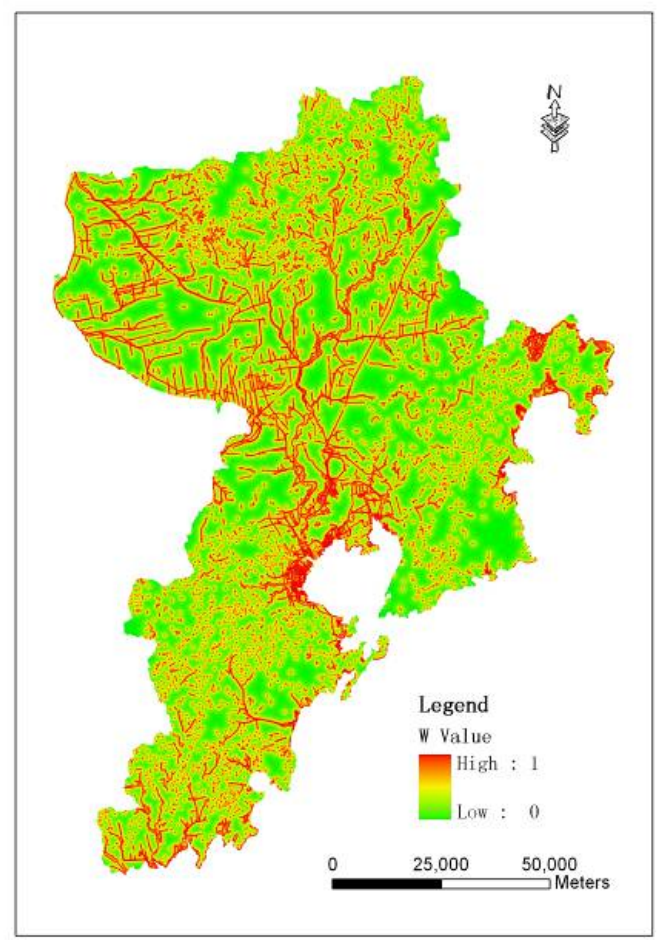

Fig. 5. The map of river factor

Then we run the ArcGIS 9.2 Spatial Analyst module to make the four factors mentioned above multiplicative and generate the non-point source pollution risk map. The values of the map range from 0.00 - 29.430. Finally, according to statistical rules, using the mean and 1 and 2 standard deviations, we make the result into four categories for statistical and mapping and get the non-point source pollution risk classification tables (Table 3) and distribution map (Figure 6).

Table 3. The non-point source pollution risk classification tables

\begin{tabular}{lll}
\hline \multicolumn{1}{c}{$\begin{array}{c}\text { Risk } \\
\text { classification }\end{array}$} & Grid value & $\begin{array}{l}\text { Area } \\
\text { proportion }\end{array}$ \\
\hline Safe region & $0-0.005$ (below average) & $69.08 \%$ \\
Low risk region & $0.005-0.035(0-1$ standard deviations above the mean) & $18.42 \%$ \\
Middle risk region & $0.035-0.065(1-2$ standard deviations above the mean) & $4.38 \%$ \\
High risk region & $0.065-29.430(>2$ standard deviation) & $8.11 \%$ \\
\hline
\end{tabular}




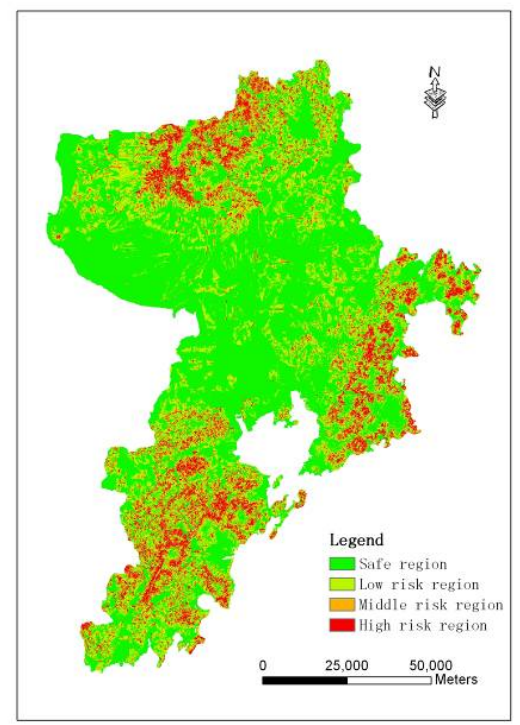

Fig. 6. The non-point source pollution risk distribution map of the study area

\section{Conclusion and Outlook}

This study describes the development process and the basic method of the study of the non-point source pollution and introduces the application of the spatial information technology in the non-point source pollution research. On this basis, we collect a variety of spatial data of the study area and use the MUSLE equation to divide the study area into safe region, low risk region, middle risk region and high risk region. The results show that the more serious regions of the non-point source pollution in the study area distribute in mountainous and hilly areas, where is steeper, has more developed river system and is prone to runoff, so these area has higher risk to bring non-point source pollution.

In this study, we use the spatial model to study the non-point source pollution. It is showed that the spatial model requires few amount of data, saves time and labor, is simple and with full scientific. Although it can not calculate a specific non-point source pollution load, it gives the risk area of the non-point source pollution. So this study provide a strong basis to facilitate the non-point source pollution management and control for environmental managers and policy makers. We can see that the spatial information technology is a powerful tool to study the non-point source pollution and will be indispensable and play an important role in the future.

\section{Acknowledgments}

Project supported by the Science and Technology Projects of Qingdao (09-1-1-53-nsh and 08-2-1-36- nsh). 


\section{References}

[1] Wang, X.Y.: Theory and Methods of Quantitative Study on Non-Point Pollution. Journal of Capital Normal University (Natural Science Edition) 17, 91-95 (1996)

[2] Vladimir, N., Gordon, C.: Handbook of Nonpoint Pollution Sources and Management, 1st edn. Van Nistrand Reubhold Company, New York (1981)

[3] National Water Quality Inventory: Report to Congress Executive Summary, USEPA, Washington (1995)

[4] Jin, X.C., Liu, S.K., Zhang, Z.S.: China Lake Environment, 1st edn. China Ocean Press, Beijing (1995)

[5] Wang, X.Y.: Non-point source pollution and its management, 1st edn. China Ocean Press, Beijing (2003)

[6] Wischmeier, W.H., Smith, D.D.: Predicting rainfall erosion losses. a guide to conservation planning. Agriculture Handbook No. 537, U.S. Department of Agriculture, USDA, Washington (1978)

[7] Arnold, J.G., Allen, P.M., Bemhardt, G.A.: A comprehensive surface-groundwater flow model. Journal of Hydrology 14, 47-69 (1993)

[8] Xia, Q.: Calculation of non-point source pollution load in the watershed mode. China Environmental Science 5, 23-30 (1985)

[9] Shan, B.Q., Yin, C.Q., Bai, Y.: Study on phosphorus load from a watershed with rainfall simulation method. Acta Scientiae Circumstantiae 20, 33-37 (2000)

[10] Cai, C.F., Ding, S.W., Shi, Z.H.: Prediction on soil nutrients losses at typical small wate rshed of three gorges area with gis. Journal Of Soil And Water Conservation 5, 9-12 (2001)

[11] Bao, Q.S., Wang, H.D.: China's non-point source pollution of water environment research and prospects. Scientia Geographica Sinica 16, 66-71 (1996)

[12] Liu, F., Wang, H.D., Liu, P.T.: Watershed non-point source pollution identification and quantification in the Yuqiao Reservoir Basin. Acta Geographica Sinica, 329-339 (1988)

[13] Liu, Y., Zhang, T.Z., Chen, J.I.: Discussion on charge policy for governance of agricultural non-point source pollution in dianchi watershed". Journal of Xiamen University (Natural Science) 11, 787-790 (2003)

[14] Pan, G.X., Jiao, S.J., Li, L.Q.: Effect of longterm fertilization practices on mobility of phosphorus in a huangnitu paddy soil receiving low $\mathrm{P}$ input in the Taihu lake region, Jiangsu province. Chinese Journal of Environmental Science 3, 91-95 (2003)

[15] Yan, W.J., Bao, X.: Study on agricultural movement of Chaohu lake basin and non-point source pollution. Journal of Soil and Water Conservation 12, 128-132 (2001)

[16] Wang, S.P., Yu, L.Z., Xu, S.Y.: Research of non-point sources pollution loading in suzhou creek. Research of Environmental Sciences 27, 20-23 (2002)

[17] Zhen, Y., Wang, X.J.: Advances and prospects for nonpoint source pollution studies. Advances in Water Science 13, 105-110 (2002)

[18] Sivertun, A., Reinelt, L.E., Castensson, R.: A GIS method to aid in non-point source critical area analysis. International Journal of Geographical Information Systems 2, 365-378 (1988)

[19] McElroy, A.D., Chiu, S.Y., Negben, J.W.: Loading functions for assessment of water pollution from non-point sources, 1st edn. US Environmental Protection Agency, Washington, DC (1976) 